\title{
Study finds relatively low emissions of methane from major US gas fields
}

\begin{abstract}
After a series of alarming reports, scientists estimate leak rate of about $1 \%$ for three major US gas formations.
\end{abstract}
Jeff Tollefson

19 February 2015

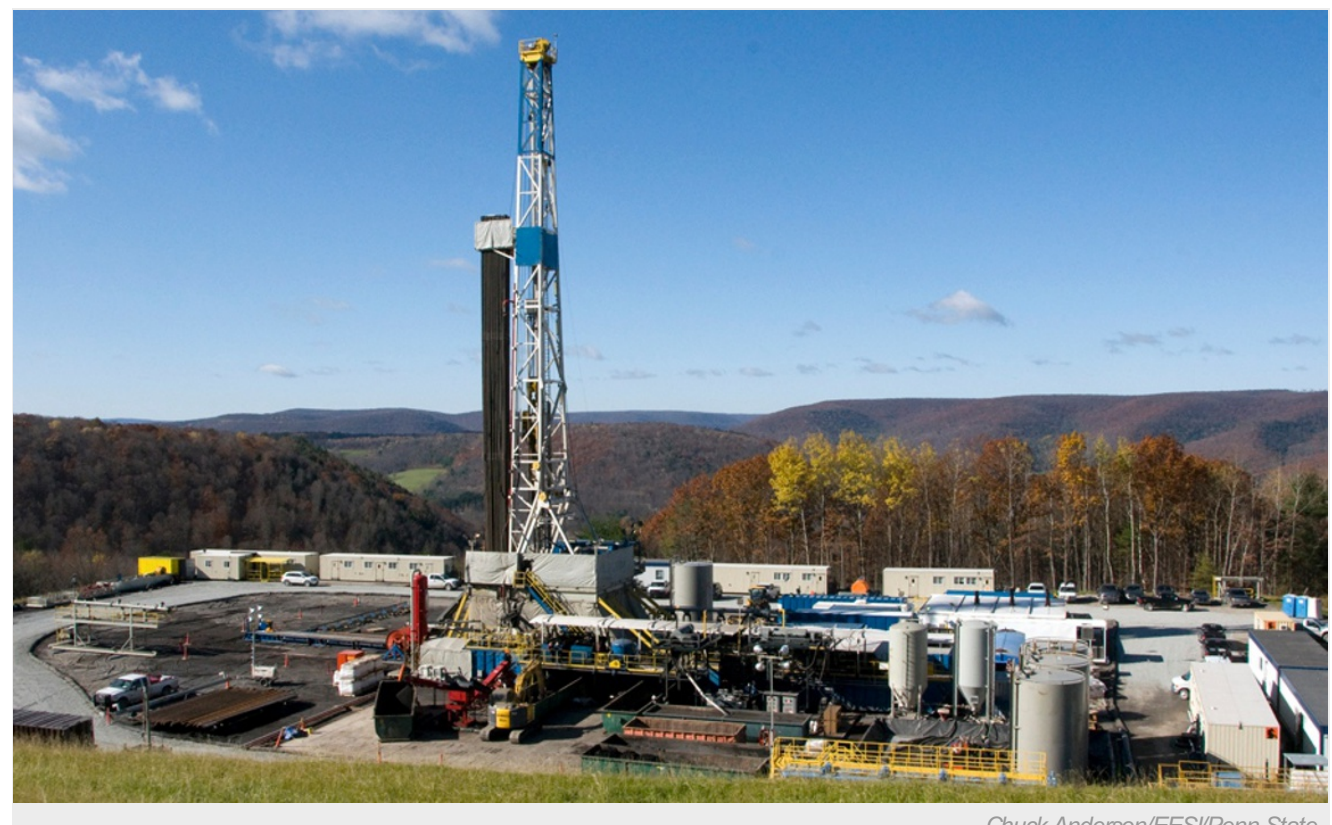

Chuck Anderson/EESVPenn State

Natural gas is pumped from the Marcellus shale formation in Tioga County, Pennsylvania.

Data show that methane emissions from major natural-gas fields in the eastern and central United States are relatively low, suggesting that overall methane emissions from gas production may not be as high as feared.

Total methane emissions from three regions — the Haynesville, Fayetteville and Marcellus formations — average about $1 \%$ of the gas produced there. That is roughly in line with US government estimates and lower than similar measurements for older fields in the West, according to a study published on 18 February in the Journal of Geophysical Research ${ }^{1}$.

These formations are responsible for roughly $20 \%$ of the total US natural-gas production, and $50 \%$ of shale-gas production, which relies on hydraulic-fracturing techniques.

"It's good news for the atmosphere and for the industry's bottom line," says lead author Jeff Peischl, an atmospheric chemist at the Cooperative Institute for Research in Environmental Sciences at the University of Colorado Boulder. His team used an instrumentequipped aircraft to monitor emissions over the formations.

Previous research ${ }^{2}$ has estimated that US methane emissions could be 1.5 times official estimates. Higher emissions during natural gas production decreases the climate benefits of shifting from coal to cleaner-burning natural gas.

Experts credit Peischl and his team's study with providing new data on important gas-producing regions, but cautioned against extrapolating too much from a snapshot of emissions at any particular location. "We have to remember that this is one study in what is now becoming a large body of scientific literature," says Steven Hamburg, chief scientist at the Environmental Defense Fund, which is based in New York City. The advocacy group is participating in a series of studies into methane emissions from the natural-gas sector.

\section{Gas leaks}

Peischl's team collected atmospheric data on methane and other pollutants in 2013 , and then calculated methane emissions by comparing concentrations of pollutants both above and upwind of the natural-gas production sites. They estimated that $1.1 \%$ of the 
natural gas produced in the three fields is leaking into the atmosphere; this figure is similar to calculations based on industry data and emissions estimates from the US Environmental Protection Agency.

Earlier studies ${ }^{3}$ suggested that methane emissions could account for about $4 \%$ of the total production at an older field in Colorado and significantly more in two other older fields. Peischl says that the lower numbers in the eastern US shale-gas fields could be attributable in part to the age of the infrastructure and differences in the types of natural gas and other hydrocarbons produced.

The emissions calculated for two of the regions - the Haynesville formation on the border of Texas and Louisiana and the Fayetteville formation in Arkansas — registered as high as $2.1 \%$ and $2.8 \%$ of the total gas produced at those sites, respectively. This is still well above what would be expected on the basis of federal emissions inventories. By contrast, the Marcellus formation, which covers several northeastern states, came in sharply lower, at $0.18-0.41 \%$ of total production.

"If that's really true, it would be worth investigating why," says Steven Wofsy, an atmospheric scientist at Harvard University in Cambridge, Massachusetts. "This is a good study, but one would want to be cautious about the results."

Hamburg says the key is to drill down into details and understand where the emissions are coming from. "Then we can get into a constructive debate about how we can reduce those emissions," he says.

Nature I doi:10.1038/nature.2015.16961

\section{References}

1. Peischl, J. et al. J. Geophys. Res. Atmos. http://dx.doi.org/10.1002/2014JD022697 (2015).

2. Miller, S. M. et al. Proc. Natl Acad. Sci. USA 110, 20018-20022 (2013).

3. Pétron, G. et al. J. Geophys. Res. Atmos. 117, D04304 (2012). 